\title{
Kanatlı İşletmelerinden Kaynaklanan Koku Probleminin Belirlenmesinde Bir E-Burun Sisteminin Kullanılması
}

\author{
Kübra Sezen, Ünal Kız1l* \\ Çanakkale Onsekiz Mart Üniversitesi, Ziraat Fakültesi, Tarımsal Yapılar ve Sulama Bölümü \\ 03.08.2017 Geliş/Received, 06.10.2017 Kabul/Accepted
}

\section{Özet}

Hayvansal üretimin çevreye olan etkileri arasında gübre kaynaklı koku, özellikle kanatlı işletmelerinde karşımıza büyük bir problem olarak çıkmaktadır. Gübre işletim sistemlerinin tasarımında ve yönetiminde dikkate alınması gereken koku probleminin başlıca kaynağı hayvan gübresinden yayılan gazlar, uçucu organik bileşikler ve diğer bazı unsurlardır. Dolayısıyla, bu probleme neden olan unsurlar koku probleminin dışında barınak içerisindeki hayvanların ve çalışan işçilerin sağlıkları üzerinde de olumsuz etkilere sahip olmaktadır. Koku son derece sübjektif bir kavram olduğundan ölçülmesi ve şiddetinin belirlenmesi oldukça güçtür. Son yıllarda elektronik alanındaki gelişmelere bağlı olarak insan burnunu taklit ederek çalışan elektronik burun sistemleri (EBS) de bu amaçla kullanılmaktadır.

Bu çalışmada, elektronik burun sistemi ile hava kalitesi ölçüm ve uyarı cihazları eş zamanlı kullanılarak, her iki sistemin performansı karş̧laştırılmıştır.

Seçilen bir kanatlı işletmesinin çevresinden alınan hava örnekleri, her iki cihazla da okunarak elde edilen değerler, coğrafi bilgi sistemi kullanılarak noktalanmış ve kokunun dağılımı yüzey istatistiği yöntemiyle modellenmiştir.

Anahtar Kelimeler: elektronik burun, gaz sensörü, hava kalitesi, koku, kümes

\section{Use of an E-Nose System in the Determination of Odor Problem Generated from Poultry Operations}

\begin{abstract}
Among the environmental impacts of livestock production, especially poultry operations, manure related odor problems appear to be highly important. Major source of odor that should be considered in the design and management of manure management systems are gases, volatile organic compounds and some other particles. Hence, those sources that causes odor and health problems for housed livestock and workers. It is highly difficult to identify and measure the level of odor since it is a subjective term. Electronic nose systems (ENS) that mimic human olfaction have been widely used in this area depending on the recent advances in electronics. The aim of this study is to compare the performance of an electronic nose system with an air quality sensing module by using these both systems simultaneously.

Air quality samples were collected from a poultry house's surroundings. Each sample was subjected to both systems simultaneously. Those readings were applied to Geographical Information Systems to spatially model the odor dispersion using geostatistics.
\end{abstract}

Keywords: air quality, e-nose, gas sensor, odour, poultry housing

*Sorumlu Yazar (Corresponding Author): Ünal Kızıl

(e-posta: unal@ comu.edu.tr)

Bu makale; Çanakkale Onsekiz Mart Üniversitesi Bilimsel Araştırma Projeleri Koordinasyon Birimince desteklenmiştir. Proje numarasi: 703 


\section{Giriş}

Dünya nüfusundaki artışa bağlı olarak artan tüketim, entansif üretimi kaçınılmaz kılmıştır. (Görgülü ve ark., 2009). Entansif tarımın sonucu olarak özellikle hayvancılık işletmeleri çevresel problemlere neden olabilmektedir. Bunlardan en önemlilerinden biri de hava kalitesi ile ilgili problemlerdir. Hayvancılık işletmelerinde hava kalitesinin gözlemlenmesi, gerek ziraat mühendisleri gerekse veterinerler için oldukça önemlidir. Çünkü hava kalitesinin izlenmesinin hem hayvanları etkileyen çevresel koşulların kalitesine hem de hayvan sağlığına etkileri son derece önemlidir (Wathes ve ark., 1997). Kokunun başlica kaynağı ise hayvan gübresidir. Tarımsal faaliyetler içerisinde hayvansal üretim sonucu önemli ölçüde gübre açığa çıkmaktadır. Gübre, kurallara uygun olarak değerlendirildiğinde bitki besin elementleri içeriğinin yüksek olmasından dolayı ekonomik bir değere sahip olmaktadır. Ancak gübre, bir işletim planlaması kapsamında bertaraf edilmediği koşullarda havza bazında su kaynaklarının kirlenmesine ve koku başta olmak üzere hava kalitesi problemlerine neden olabilmektedir. Bu bağlamda, gübre işletim planlaması kapsamında en önemli konulardan bir tanesi de koku problemini kontrol altında tutmaktır (Vac ve ark., 2013; GD 780, 2006). Kokunun şiddetinin zaman içinde değişiklik göstermesinden ve düşük konsantrasyonların ölçülmesinin güçlüğünden dolayı objektif bir biçimde belirlenmesi ve ölçülmesi oldukça güçtür. Kokunun belirlenmesinde kullanılabilecek oldukça farklı sensör çeşitleri mevcuttur. Bunlardan bazıları; temaslı polimerler, piezoelektrik cihazlar, elektrokimyasal hücreler ve metal oksit sensörlerdir (Brattoli ve ark., 2011).

Hava kalitesiyle ile ilgili yapılan çalışmalarda son yıllarda e-burun sistemleri yaygın olarak kullanılmaktadır. Günümüz teknolojik koşullarında, elektronik bilimi ve sinir ağları algoritmalarındaki gelişmeler ışığında canlı ve materyallerin bazı özelliklerinin ölçülmesi ve sınıflandırılması kolaylıkla gerçekleştirilmektedir. Elektronik burunlar, insanlardaki kokunun duyu oluşturması mekanizmasına benzer şekilde çalışmaktadır. Çok aşamalı bir sistemi ifade eden insanda kokunun duyu oluşturması mekanizmasında burundaki algılayıcı hücreler birincil sistem parçalarıdır ve elektronik burunlarda bunların yerini sensörler almıştır (Barisci ve ark., 1997; Panigrahi ve ark., 2002).

$\mathrm{Bu}$ çalışmada elektronik burun sistemlerinin kümeslerden kaynaklanan koku probleminin tespiti ve şiddetinin belirlenmesi amacıyla bir yöntem geliştirilmek hedeflenmiştir. Sensör teknolojileri, Coğrafi Bilgi Sistemleri (CBS) ve yüzey istatistiği yöntem ve teknolojileri bu doğrultuda değerlendirilmiştir. Bu bağlamda, ticari olarak satılan DiagNose II metal-oksit gaz sensörlerinden oluşan bir elektronik burun sisteminin kümeslerden kaynaklanan koku probleminin alansal olarak etkilerinin belirlenmesindeki potansiyeli araştırılmıştır. Hava örnekleme cihazı ile belli noktalarda toplanan örnekler laboratuvar ortamında elektronik buruna koklatılmış ve yüzey istatistiği haritaları ile her bir sensörün verdiği tepki alansal olarak görsellenmiştir.

\section{Materyal ve Metot}

\subsection{Materyal}

\subsection{1. Çalışma Alanı}

Çalışma kapsamında seçilen barınak; Çanakkale İli, Merkez İlçesi, Dümrek Köy sınırları içerinde, köy merkezine 600 metre uzaklıktadır (Şekil 2.1). Çanakkale İlinin güneyinde yer alan işletme 17 yıldır aktif olarak etlik piliç üretimi yapmaktadır. İşletme, yaklaşık $8000 \mathrm{~m}^{2}$ alan üzerinde kurulu olup üretim kapasitesi 48000 tavuktur. 


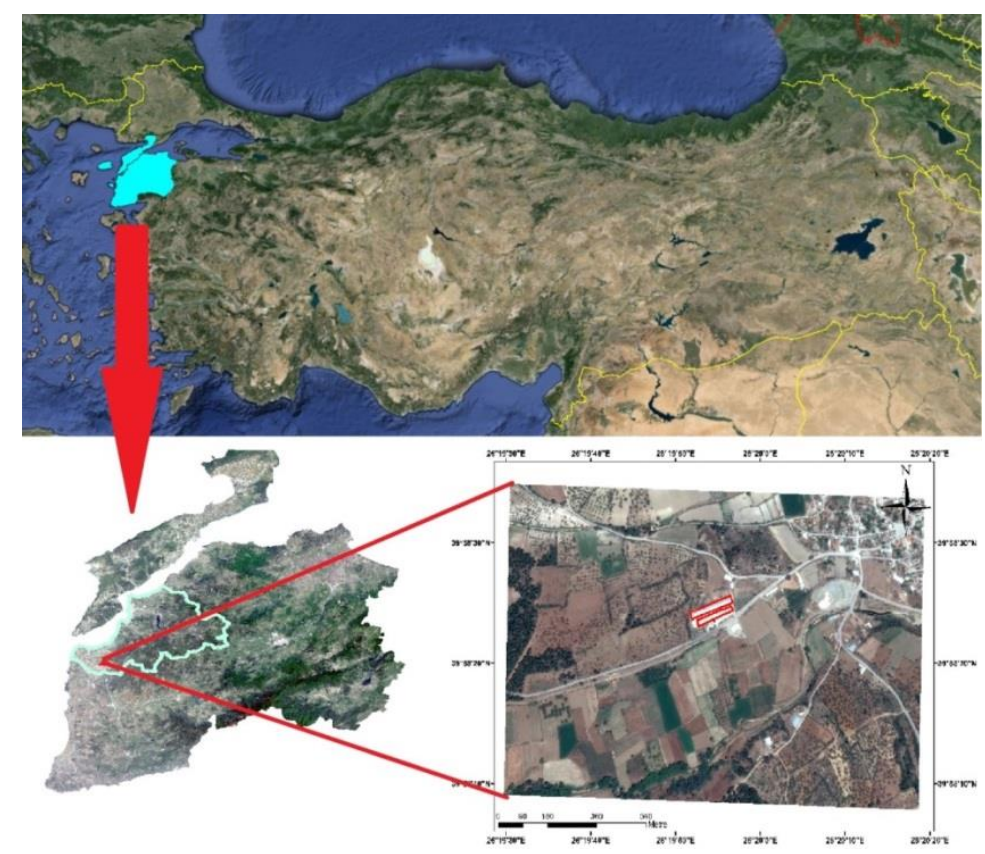

Şekil 2.1. İşletme konumunu gösterir harita.

\subsubsection{Elektronik Burun}

Çalışma kapsamında kullanılan e-burun, ticari olarak temin edilmiş DiagNose II (The eNose Company, Zutphen, Hollanda)'dir. İçinde 12 adet yarı iletken özellikli metal oksit sensör barındıran bu elektronik burun, geniş bir spektrumda uçucu hidrokarbonlar ve inorganik molekülleri algılayabilmektedir. Sensör yüzeyine etkiyen gaz konsantrasyonu değişimlerini, sensör üzerinden geçen akımdaki değişimle ilişkilendirerek sinyal üretmektedir. Oluşturulan sinyalleri dâhili hafizasında saklayan cihaz, EPO yazılımı (The eNose Company, Zutphen, Hollanda) vasıtasıyla bilgisayara aktarmaktadır. Zamana bağlı üretilmiş sinyaller grafik üzerinden ya da sayısal değerler olarak işlenerek kullanılabilmektedir.

\subsubsection{Hava Kalitesi Sensör Modülü}

Hava kalitesinin izlenmesinde kullanılan AM-1-2600 (Figaro Engineering Inc., Osaka, Japonya) modülü, TGS2600 sensör ve bir mikro kontrol ünitesinden oluşmaktadır. Endüstriyel amaçlarla kullanılmakta olan bu modül, gerçek kirlilik miktarını göstermek yerine sensör çıktılarını ön tanımlı seviyelerle karşılaştırarak 4 farklı durumu işaret etmektedir. Sensör sinyallerine göre, 1 temiz ve 3 kirli hava sinyali üreten modül, çalıştırıldıktan kısa bir süre sonra hazır duruma geçmekte ve ortamdaki gaz konsantrasyonunu temiz hava eşiği olarak belirlemektedir. Ortamdaki gaz konsantrasyonu, sensör çıkış sinyalinde, öntanımlı çarpanlara eşit değiş̧ime uğradığında sırasıyla 3 alarm seviyesini işaret etmektedir.

\subsubsection{Hava Örnekleme Kiti}

Barınak çevresinde belirlenen noktalardan, hava örneklerin alınması ve analiz edilene kadar bozulmadan saklanabilmesi gerekmektedir. Bu bağlamda, ticari olarak bulunabilen ve hava örnekleri ile etkileşime girmeyen malzemeden imal edilmiş SKC vakumlu odacık ve örnek poşetleri (SKC Inc., Pennsylvania, ABD) kullanılmıştır. Kalın polietilen malzemeden üretilen ve hava sızdırmayacak şekilde modifiye edilmiş vakumlu odacık, çelik valfler ve gözlem için dairesel bir pencereden oluşmaktadır. Kitle birlikte gelen şarjlı pompa, kilitli valflere 
bağlanarak odacığın içindeki havayı ayarlanan süratle tahliye etmektedir. Odacığın içine yerleştirilen ve dış ortama doğrudan bağlantısı olan örnekleme poşetleri, odacığın içerisindeki hava tahliye oldukça oluşan negatif basıncın etkisiyle şişmekte ve dış ortamdaki havayı içine almaktadır. Bu sayede, örnek poşetinin içine alınan gazın sıcaklık ve nem gibi fiziksel özellikleri değişmeden, kimyasal etkileşime girmeden saklanması sağlanmaktadır. Örnekleme poşetlerinin bağlantı noktasında bulunan tek yönlü valf sayesinde içeri alınan hava karışımının dışarı boşalması da engellenmektedir.

\subsection{Yöntem}

Çalışma kapsamında kullanılan materyal ve çalışma planını içeren akış diyagramı Şekil 2.2'de gösterilmiştir. Buna göre, çalışmanın yürütüleceği barınağın tespit edilerek detaylı bilgi ve materyalin elde edilmesi ön çalışma kısmını oluşturmaktadır. Ön çalışma da elde edilen veriler doğrultusunda, örnekleme için uygun noktalar belirlenmiştir. Hava örnekleme işlemi gün içerisinde tamamlanarak arazi çalışması sonlandırılmıştır. Laboratuvara getirilen örnek poşetleri uygun koşullarda muhafaza edilerek aynı gün içinde Diagnose II ve AM-1-2600 okumaları yapılmıştır. Bilgisayara aktarılan sensör değerleri normalizasyon işleminin ardından CBS yazılımına aktarılarak yüzey istatistiği uygulanmış ve oluşturulan haritalarla laboratuvar çalışmaları sonlanmıştır. Barınağın konumu, kaydedilen meteorolojik veriler ve sensör sonuçları göz önüne alınarak, çalışma bulguları tartışılmıştır.

\subsubsection{Hava Örneklerinin Alınması}

Hazırlanan düzenek sayesinde her bir örnekleme noktasında 1 adet örnek poşeti kullanılmasının yeterli olacağı görülmüştür. Mevcut örnek poşeti sayısına göre 40 noktadan hava örneği alınabileceği belirlenmiştir. Haritalama programı vasıtasıyla elde edilmiş uydu görüntüsü üzerinde, arazide yapılan ön keşif işlemlerinde belirlenen ulaşılabilir bölgeler göz önüne alınarak, bu bölgelerdeki örnekleme noktaları homojen bir şekilde işaretlenmiştir. Örneklemelerin, belirlenen noktalardan yapılabilmesi için koordinatları el tipi GPS'e (GARMIN GPSmap 60CSx, Garmin Ltd, Kansas, ABD) yüklenmiştir. Böylece, arazideki noktaların $30 \mathrm{~cm}$ doğrulukla belirlenebilmesi sağlanmıştır. Her bir nokta GPS ile tespit edildikten sonra etiketlenen örnek poşetleri basınç odacığının içine yerleştirilerek mühürlenmiştir. Ortalama 2 dakika süren örneklemeler esnasında bir anemometre (TROTEC BA15, TROTEC GmbH \& Co., Heinsberg, Almanya) yardımıyla rüzgar hızı ve hava sıcaklığ da ölçülerek kaydedilmiştir. Örneklemenin sonunda basıncı tahliye edilen odacığın içerisinden alınan örnek poşetleri siyah çöp poşetinde muhafaza edilerek direkt güneş 1şığına maruz kalmaları engellenmiştir. Örnekleme işinin tamamlanmasının ardından laboratuvara taşınan örnek poşetleri serin ve rutubetsiz bir ortamda muhafaza edilmiştir. 


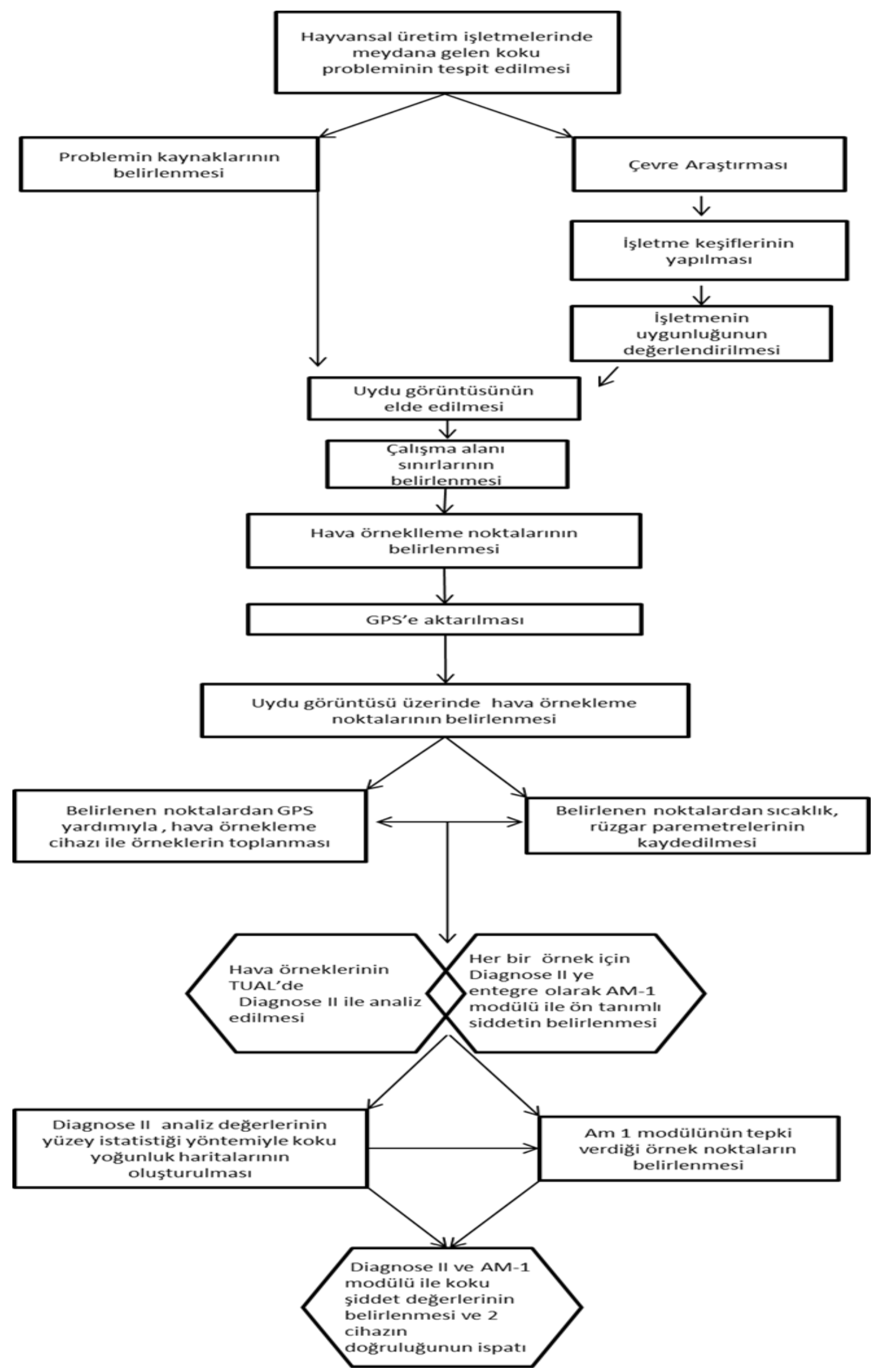

Şekil 2.2. Çalışmanın akış diyagramı. 


\subsubsection{Hava Örneklerinin Analiz Edilmesi}

Barınak çevresinden toplanan hava örnekleri e-burun ve hava kalitesi izleme cihazında analiz edilmek üzere Tarımsal Sensör ve Uzaktan Algılama Laboratuvarına (TUAL) getirilmiştir. Örnek poşetleri, e-burun ölçüm gaz girişine doğrudan bağlanmıştır. E-burun örnek gaz çıkışı ise içinde hava kalitesi izleme cihazı bulunan hava geçirmez kap içine yönlendirilmiştir (Şekil 2.3).

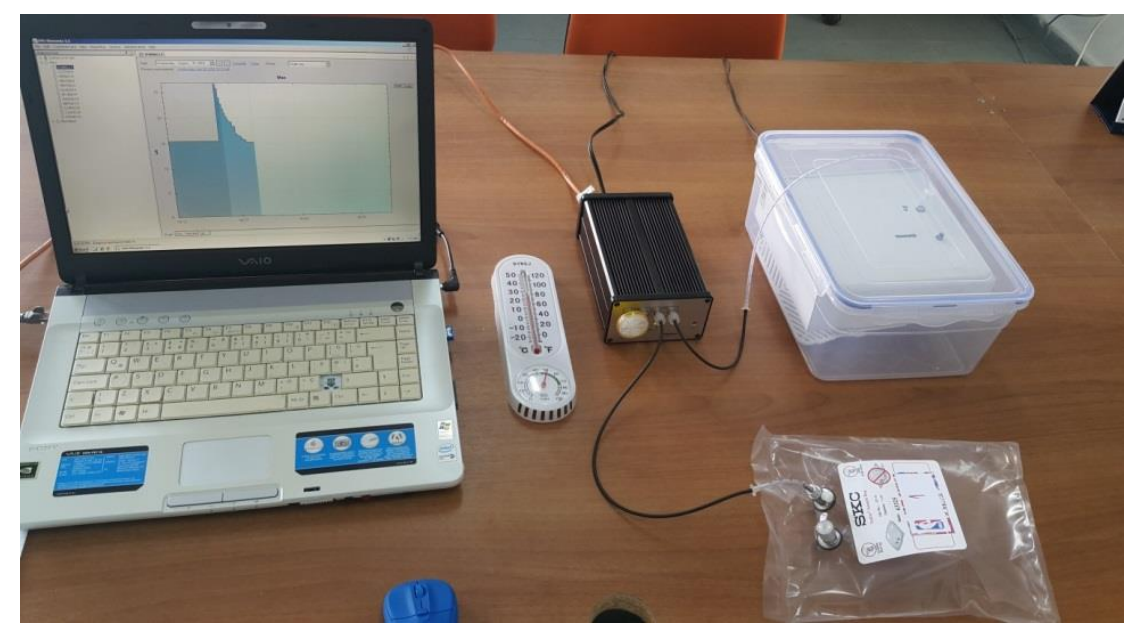

Şekil 2.3. Hava örneklerinin laboratuvar koşullarında analiz edilmesi.

Elektronik burun okumaları, cihaz bilgisayara bağlıyken yapılmış ve veriler zamana bağlı olarak okunabilmiştir. Okumalar esnasında hava kalitesi izleme cihazının sinyalleri ve okuma zamanları kayıt altına alınmıştır.

Okumalar esnasında 2 adet örnek poşetinin içinde yeterli miktarda gaz örneği bulunmadığı görülmüş ve analiz dışı bırakılmıştır.

\subsubsection{Yüzey İstatistiği Haritalarının Oluşturulması}

Barınak çevresinin koku haritalarını oluşturmak için ArcGIS 10.3 (ESRI Inc., Kaliforniya, ABD) coğrafi bilgi sistemi yazılımı kullanılmıştır. Coğrafi olarak işaretlenmiş noktalardan alınan hava örneklerinin analiz sonuçları, yazılımda değerlendirilerek bölgeyi temsil edecek haritaların oluşturulmasında Kriging metodu kullanılmıştır. ArcGIS programı, yüklenen tablo verileriyle sade, basit ve kapsamlı Kriging modellerinin birine göre görseller oluşturulmasını sağlamaktadır. Verilerin niteliği ve sayısı, kullanılacak modelin seçimini sağlamaktadır. Çalışma kapsamında elde edilen ve istatistiksel olarak işlenen veriler sürekli veriler olup örnekleme şekline göre geometrik ortalamaya uygundur. Bu nedenle kullanılan yöntem basit Krigingtir.

Basit Kriging işlemi için bölgesel çarpanların oluşturulması gerekmektedir. $\mathrm{Bu}$ çarpanlar, eldeki verilerin konumsal yoğunluğundan ve değerliklerinden yola çıkılarak oluşturulur (Davis ve Culhane, 1984). Bunun için bir yarı variogram kullanılır (Bras ve Rodriguez-Iturbe, 1985). Sayısal veri girdileri ile oluşturulmuş karekök ortalamaları doğrultusunda gereken model seçilir. Seçilen modelin doğrulanması, çapraz doğrulama ile yapılır (Davis ve Culhane, 1984).

Seçilen Kriging ve yarı variogram modelleri doğrultusunda bilinmeyen noktalar için veri oluşturulması eşitlik 1 e göre yapılır.

$$
\mathrm{Z}^{*}(\mathrm{x})=\sum_{\mathrm{i}=1}^{\mathrm{n}} \lambda_{\mathrm{i}} \mathrm{Z}\left(\mathrm{x}_{\mathrm{i}}\right)
$$


Eşitlikte;

$\mathrm{Z}\left(\mathrm{x}_{\mathrm{i}}\right), \mathrm{x}_{\mathrm{i}}$ noktasındaki $\mathrm{Z}$ değişkeninin gözlenen değerini; $\mathrm{Z}^{*}(\mathrm{x})$, $\mathrm{x}$ noktasındaki $\mathrm{Z}$ değişkeninin tahmini değerini; $x$, tahminlenen noktanın koordinatlarını; $x_{i}$, gözlemlenen $i$ değerinin koordinatlarını; $\mathrm{n}$, tahminlemede kullanılan değer sayısını; $\lambda_{\mathrm{i}}$ : gözlemlenen $\mathrm{i}$ değerinin ağırlığını ifade eder. Bu katsayının hesaplanması ise eşitlik 2 ye göre yapılır (Hosseini ve ark., 1993).

$$
\lambda_{i}=\frac{D_{i}^{-a}}{\sum_{i=1}^{n} D_{i}^{a}}
$$

Eşitlikte;

$D_{i}$, gözlemlenen i noktası ile interpolasyon bölgesi arasındaki mesafeyi; $\alpha$ ise mesafe ağırlık kuvvetini ifade eder.

Açık kaynaklı harita programından elde edilen uydu görüntüsü, ArcGIS programında haritaların görselini oluşturmak üzere koordinat sisteminde kaydedilmiştir. $\mathrm{Bu}$ sayede, örnekleme noktaları vektörel olarak görselleştirilebilmiştir. E-burun okumalarından elde edilen tablo değerleri ve hava kalitesi izleme cihazının alarm kategori bilgileri, örnek noktalarının özellik içeriği olarak eklenmiştir. Örnekleme noktalarının koordinat sistemine uygun biçimde yerleştirilmesi ve analiz sonuçlarının işlenmiş olması sayesinde, yüzey istatistiği metoduna göre alanın koku dağılım haritaları olușturulabilmiștir. Bu haritaların daha kolay anlaşılabilmesi için sınıflandırma, her bir sensör modülünde geometrik aralık esasına göre 3 grupta düzenlenmiştir. Sınıfların renklerle kodlanması ve altlık olarak kullanılan uydu görüntüsü sayesinde, barınak çevresinin koku dağılımı, bölgesel olarak yorumlanabilir duruma getirilmiştir.

\section{Bulgular ve Tartışma}

E-burun sistemlerinin kullanılmasıyla gerçekleştirilecek koku gözlemi ile ilgili çalışmalar hem çevre hem de hayvan/insan sağlığı bakımından oldukça önemlidir. Bu sistemler hayvansal üretim sonucu açığa çıkan gübrenin çevreye olan olumsuz etkilerini en aza indirmek amacıyla gübre işletim planlaması kapsamında da ele alınmalı ve koku kontrolü ile hayvansal atık yönetimi konularını da kapsayacak şekilde planlamalar yapılmalıdır.

Kanatlı işletmelerinde, özellikle sıcak mevsimlerde havalandırmanın artmasıyla birlikte civarda belirginleşen rahatsız edici kokuların saptanması, önleyici tedbirlerin alınmasını zorunlu kılmaktadır. Son yıllarda alınacak tedbirlerin etkinliğini arttırmak adına gelişen teknolojilerden yoğun olarak istifade edilmektedir. Bu kapsamda yürütülmüş çalışmada, ticari olarak elde edilebilen bir elektronik burun sistemi ile ucuz ve pratik bir hava kalitesi izleme cihazı birlikte kullanılmıştır. Barınak çevresinde belirlenen noktalardan örneklenen hava, iki cihazla da analiz edilerek sonuçların karşılaştırılabilmesi adına yüzey dağılım haritaları oluşturulmuştur. Örneklemeler esnasında anlık rüzgar şiddeti ve hava sıcaklığı verilerinin kaydedilmesi, sonuçların yorumlanmasında etkili olmuştur (Çizelge 3.1).

Örneklemeler esnasında hissedilen rahatsız edici kokunun, barınağın havalandırma açıklıklarının da bulunduğu cephe olan kuzey yönünde yoğunlaştığı görülmüştür. Benzer şekilde, barınağın doğu yönünde bulunan zeytin ağaçları ve batı yönünde bulunan karışık orman tipi ağaçların da hava hareketini kısıtlayarak hissedilen kokuyu bölgede hapsettiği kaydedilmiştir. Buna göre hissedilebilir kötü kokuyu oluşturan gaz karışım haritalarında beklenen sonuç, barınağın kuzey, kuzey-doğu ve kuzey-batı bölgelerinde yüksek konsantrasyonlarıdır.

Kullanılan elektronik burun sisteminin sensörleri kalibre edilmiş olmadığı gibi tek bir gaz için sonuçlar vermemektedir. Gazların farklı moleküler bileşikleri ve reaktif ajanlarının diğer 
gazlarla tepkimesi sonucu oluşan ürünler de sensörlerde oluşan sinyallerin seviyesini değiştirmektedir.

Çizelge 3.1. Örnekleme noktalarında kaydedilen rüzgar hızı ve hava sıcaklığı verileri

\begin{tabular}{|c|c|c|c|c|c|c|c|c|c|c|c|}
\hline $\begin{array}{c}\text { Örnek } \\
\text { Noktas! } \\
\end{array}$ & $\begin{array}{c}\text { Rüzgar } \\
\mathrm{Hiz1} \\
(\mathrm{km} / \mathrm{h})\end{array}$ & $\begin{array}{c}\text { Hava } \\
\text { Sicakllğ } 1 \\
\left({ }^{\circ} \mathrm{C}\right)\end{array}$ & $\begin{array}{l}\text { Örnek } \\
\text { Noktas } \\
\end{array}$ & $\begin{array}{c}\text { Rüzgar } \\
\text { Hız1 } \\
(\mathrm{km} / \mathrm{h}) \\
\end{array}$ & $\begin{array}{c}\text { Hava } \\
\text { Sicaklığ } 1 \\
\left({ }^{\circ} \mathrm{C}\right) \\
\end{array}$ & $\begin{array}{l}\text { Örnek } \\
\text { Noktast }\end{array}$ & $\begin{array}{c}\text { Rüzgar } \\
\mathrm{Hiz1} \\
(\mathrm{km} / \mathrm{h})\end{array}$ & $\begin{array}{c}\text { Hava } \\
\text { Sicakllğ } 1 \\
\left({ }^{\circ} \mathrm{C}\right)\end{array}$ & $\begin{array}{c}\text { Örnek } \\
\text { Noktas } \\
\end{array}$ & $\begin{array}{c}\text { Rüzgar } \\
\text { Hızı } \\
(\mathrm{km} / \mathrm{h})\end{array}$ & $\begin{array}{c}\text { Hava } \\
\text { Sicakll̆ } \\
\left({ }^{\circ} \mathrm{C}\right) \\
\end{array}$ \\
\hline 1 & 4 & 33.6 & 11 & 13 & 37.7 & 21 & 1.9 & 39.4 & 31 & 1.9 & 33.5 \\
\hline 2 & 2.9 & 34.3 & 12 & 4 & 33.3 & 23 & 3.4 & 35.8 & 32 & 1 & 34.2 \\
\hline 3 & 2.8 & 33.3 & 13 & 1.5 & 34.8 & 24 & 4.2 & 33.4 & 33 & 2 & 36.1 \\
\hline 4 & 3.1 & 36.3 & 14 & 2 & 34.6 & 25 & 4.3 & 35.5 & 34 & 4 & 33.7 \\
\hline 5 & 3.6 & 33.6 & 15 & 1.7 & 36 & 26 & 2.4 & 34.3 & 36 & 1.8 & 36.5 \\
\hline 6 & 4.2 & 33.9 & 16 & 4.2 & 32.6 & 27 & 2.1 & 37.4 & 37 & 2.1 & 36.4 \\
\hline 7 & 3.4 & 36 & 17 & 1 & 38.4 & 28 & 4.1 & 35.6 & 38 & 1.7 & 35.2 \\
\hline 8 & 2.5 & 38.5 & 18 & 3 & 36.7 & 29 & 2 & 33.4 & 39 & 2 & 35.4 \\
\hline 9 & 3.1 & 38 & 19 & 2.1 & 36.5 & 30 & 2.5 & 35.6 & 40 & 3.8 & 36 \\
\hline 10 & 2.8 & 37.3 & 20 & 1.8 & 37 & & & & & & \\
\hline
\end{tabular}

Diagnose II e-burun sisteminin sonuçlarına göre değerlendirilen haritalara bakıldığında 8 adet sensörün bu doğrultuda sonuç verdiği görülmüştür (Şekil 3.1). Buna kokuya neden olan gazların konsantrasyonları yoğun olan bölgeler açık renkle boyanmış alanlar olup, azaldıkça sırasıyla haki ve yeşil renkle boyanmış alanlar ifade edilmektedir. Kümesin konumu ve boyutları, haritalar üzerinde gri asimetrik dörtgenlerle gösterilmiştir. E-burun sensörlerinin verileri voltaj (volt) okumaları olup, aynı gaz konsantrasyonlarına, değișen nem ve sıcaklık etkisiyle farklı tepkiler verebilmektedir. Buna göre, ham sensör verileri ancak kategorik olarak sınıflandırılarak karşılaştırıldığında anlamlı sonuçlar oluşturulabilmektedir. Coğrafi bilgi sistemi programında veri girdisi olarak kullanılan sensör tepkileri, Basit Kriging yöntemi ile görselleştirilmiş ve karekök ortalamaları metoduyla kategorize edilmiştir. Buna göre, farklı konsantrasyonları işaret eden renklerdeki alanlar, istatistiki olarak oluşturulmuş birimsiz sınır değerleridir.

Kriging yöntemi, kesin değerleri bilinen noktalardaki verileri kullanarak, tahmin edilmek istenen noktaları oluşturmaktadır. Buna göre, gaz konsantrasyonlarının taşındığı azami mesafeler, bilimsel olarak vurgulanabilir değildir. Elde edilen haritalar, gaz konsantrasyonlarının taşınma eğilimlerini ortaya koymaktadır. 

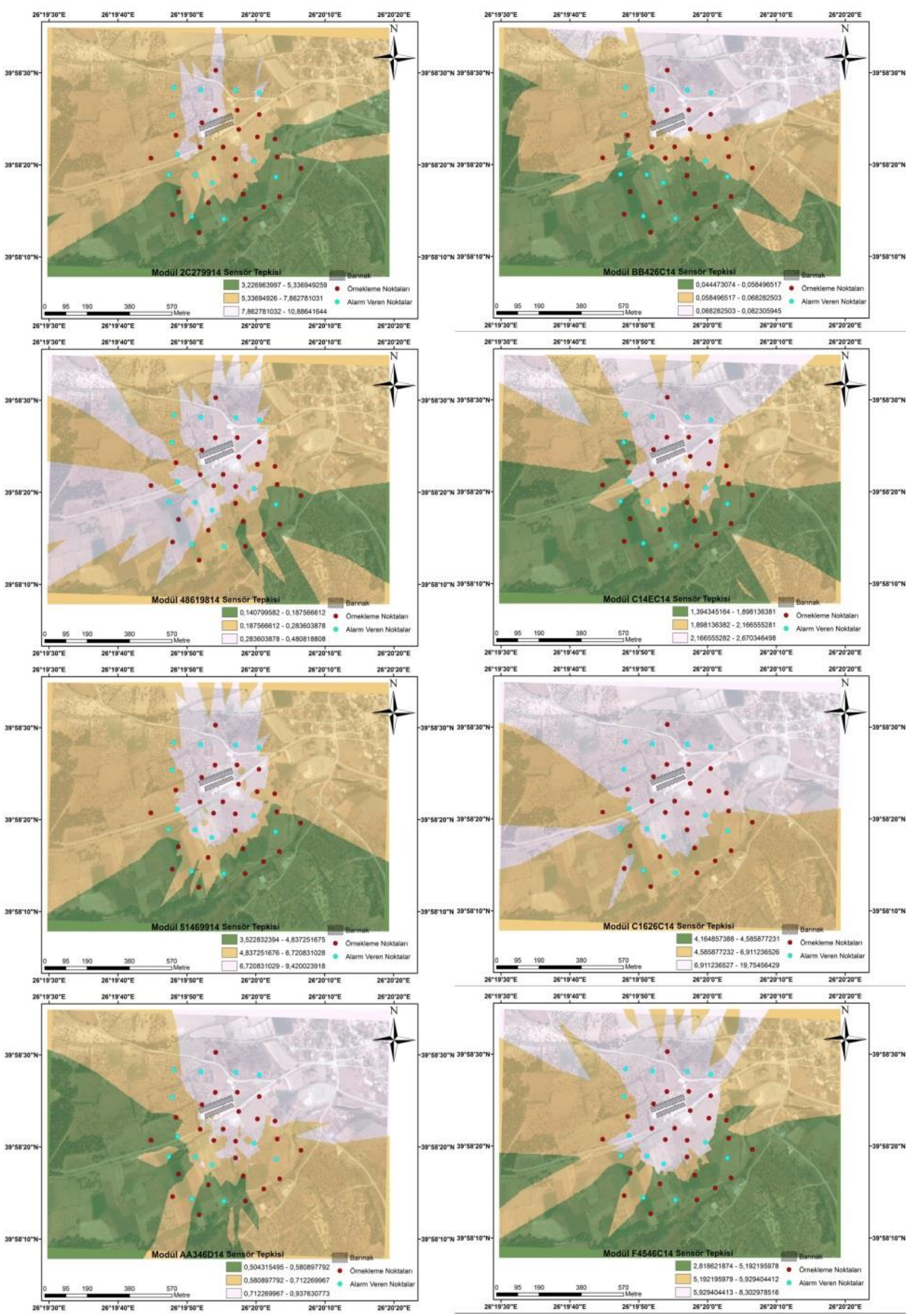

Şekil 3.1. 8 adet sensör tepkisi doğrultusunda oluşturulmuş koku haritaları. 
Barınağın çevresindeki diğer koku kaynaklarına bakıldığında; güney yönünde $350 \mathrm{~m}$ mesafede bir adet büyükbaş ve 2 adet küçükbaş hayvan barınağı mevcuttur. Örneklemeler esnasında, bu barınaklara yakın bölgelerde hissedilebilir yoğunlukta bir koku olmadığı görülmüştür. Örneklemelerin yapıldığı gün hâkim rüzgâr yönünün güney-batı olması, bu barınaklardan kaynaklanan kokunun örnekleme bölgesinin tersi yönünde hareket etmesini sağlamıştır. Bununla birlikte Diagnose II sensörlerinin 4 tanesinin oluşturduğu haritalar, kanatlı işletmesinden kaynaklanan kokunun hâkim rüzgâr yönünde taşındığını ortaya koymuştur (Şekil 3.2).

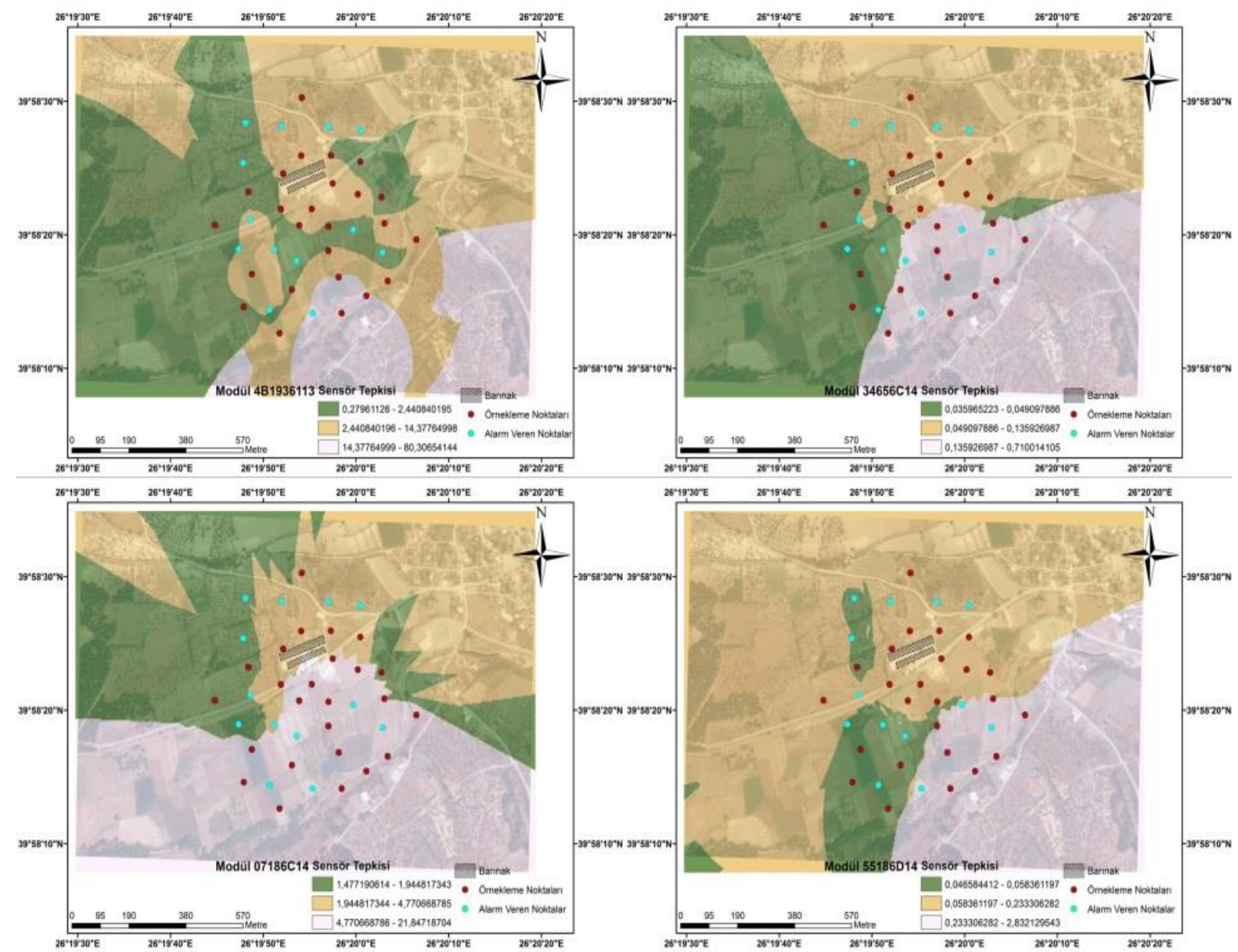

Şekil 3.2. 4 adet sensör tepkisi doğrultusunda oluşturulmuş koku haritaları.

Oluşturulmuş haritalar birlikte ele alındığında, Diagnose II elektronik burun sistemi değişen koşullar doğrultusunda kokuyu algılamakta başarılı sonuçlar verdiği görülmektedir. Atmosferik havayı oluşturan gaz karışımından daha ağır olmaları sebebiyle rüzgarla taşınımı az olan gaz bileşenlerinin tespit edilmesinde (Şekil 3.1) 8 adet sensör önemli sonuçlar verirken daha hafif olan bileşenlerin tespitinde kalan 4 sensör (Şekil 3.2) etkili olmuştur.

Örneklerin analiz edilmesi esnasında AM-1 cihazının hassasiyet ayarının ilk 14 örnekte farklı seçilmiş olması dolayısıyla barınak çevresinden alınan örneklerde alarm sinyali alınamamıştır. Kalan örneklerin okunması esnasında düzeltilen hassasiyet ayarı neticesinde, oluşturulan haritalarda alarm veren (turkuaz renkle işaretlenmiş) noktaların kuzey ve kuzey-doğu yönünde barınak çevresinde yoğunlaştığ görülmüştür. Buna göre hava hareketlerinden daha az etkilenen gaz bileşenlerinin tespitinde AM-1 cihazı etkili olmuştur. Alarm sinyali alınan diğer noktalara bakıldığında barınağın güney-batı bölgesinde toplandığı görülmektedir. $\mathrm{Bu}$ noktadan hareketle, Diagnose II sistemi tarafından belirlenen diğer gazların tespiti için de AM-1 cihazı önemli sonuçlar vermiştir. 


\section{Sonuç}

Bir broiler işletmesinden kaynaklanan kokunun barınağa olan mesafeye, diğer koku kaynaklarına, fanların konumuna, rüzgar yönüne ve diğer topografik koşullara bağlı olarak nasıl değiştiği koku dağılım haritaları çıkarılarak belirlenmiştir. Bu amaçla DiagNose II elektronik burun sistemi kullanılmıştır. Bu cihaz içinde 12 adet yarı iletken metal oksit gaz sensörü barındırmaktadır. Her bir sensörün duyarlı olduğu gaz farklıdır. Dolayısıyla cihaz içinde bulunan 12 farklı gaz sensörünün ayrı ayrı tepkisi, alanın kümülatif koku dağılım durumunu ortaya koymuştur.

Kümesin doğu ve batısı ağaçlıktır. Havalandırma fanları ise barınağın kuzeye bakan cephesinde yerleştirilmiştir. Bunun yanı sıra işletmenin güneyinde ve yaklaşık $350 \mathrm{~m}$ mesafede farklı hayvancılık işletmeleri mevcuttur. Bu bağlamda ele alındığında kokunun işletmenin kuzeyinde ve güneyinde yoğunlaşmış olacağı doğaldır. Belli noktalardan alınan hava örneklerinin laboratuvar ortamında e-burun sistemine koklatılması ile elde edilen sensör değerleri CBS ortamında noktaların koordinatları dikkate alınarak işaretlenmiştir. Yüzey istatistiği yöntemlerinden olan Kriging metodu kullanılarak her bir sensörün tepkisinin alansal dağılımı belirlenmiştir. Böylece koku dağılım haritaları oluşturulmuştur. Oluşturulan bu sensör tepki haritalarından 8 tanesinin sonuçları barınağın kuzeyindeki 4 tanesinin sonuçları da güneyindeki yoğunlaşmayı ortaya koymuştur.

Bununla birlikte, hava kalitesi ölçüm cihazının performansı da ortaya konmaya çalışılmıştır. Alınan hava örnekleri oluşturulan düzenek sayesinde e-burun sistemiyle eş zamanlı olarak hava kalitesi ölçüm cihazına da sirküle edilmiştir. Cihazın, e-burun sistemiyle benzer şekilde barınak etrafında ve özellikle kuzey ve güneyinde koku şiddetindeki artışı ortaya koyduğu gözlemlenmiştir.

Avrupa Birliği adaylık sürecindeki ülkemizin tarımsal faaliyetler içindeki en büyük eksiklerinden biri hayvansal atık yönetimi bilincinin henüz yerleşmemiş olmasıdır. Tarımsal atık yönetimi kapsamında en önemli konu hayvansal atıkların yönetimi ve işletimi konusudur. Hayvansal atıkların yönetimi ve işletimi sürecinde karşılaşılan problemlerin başında çevresel sorunlar ön plana çıkmaktadır. Koku problemi ise özellikle kanatlı yetiştiriciliğinin yapıldığı hayvancılık işletmelerinin en önemli problemlerinden bir tanesidir.

Dünyada son yıllarda yaygın olarak kullanılan ve Ziraat Fakültesi, Tarımsal Sensör ve Uzaktan Algılama Laboratuvarı bünyesinde de bulunan bir elektronik burun sisteminin Tarım Mühendisliği alanında kullanılması sağlanacak ve ülkemizde bu konudaki çalışmalara hem öncülük edilecek hem de bu konuda bir yöntem ortaya konulmuş olacaktır. Geliştirilmiş olan basit hava kalitesi ölçüm cihazının performansının e-burun ile test edilmesi sonucunda söz konusu hava kalitesi ölçüm cihazının hayvancılık işletmelerinde kullanımı mümkün olacaktır.

Geliştirilmiş olan cihaz ekonomik olmanın yanı sıra hava kalitesiyle ilgili ortaya çıkan sorunlarda işletme sahibini telefon ile arayarak uyaracağından cihazın kullanılmasıyla sorunların erkenden tespit edilmesi sağlanmış olacak ve çevre ve insan/hayvan sağlı̆̆ ile ilgili problemler en aza indirgenerek ülke ekonomisine katkı sağlanabilecektir.

Söz konusu ölçüm cihazı sadece kritik durumlarda üreticiyi uyarma özelliğine sahip olmayıp, havalandırma/serinletme sistemlerine entegre edilerek otomasyon sağlama özelliğine de sahiptir. Bu bağlamda hayvan barınaklarının havalandırması konusunda da kullanılabilecek bir sistem test edilmiş olacaktır.

Gaz sensörleri kullanılarak geliştirilmiş e-burun sistemlerinin kokunun gözlemlenmesinde kullanılabileceği bu çalışmayla ve farklı literatürle ortaya konmuştur. Bu çalışmada kullanılan e-burun sistemi pahalı ve kullanımı belli seviyede uzmanlık gerektiren bir sistemdir. Ancak, söz konusu gaz sensörleri oldukça ekonomik fiyatlarla temin edilebilmektedir. Günümüz elektronik teknolojisindeki gelişmeler e-burun sistemlerinin çok daha ucuza mal edilmesini sağlayabilecek mikrodenetleyiciler, güç üniteleri, veri depolama ve iletim ünitelerini mümkün 
kılmaktadır. Amaca özgün, ekonomik, yerli bir yazılıma sahip ve mobil koku algılayıcıların geliştirilmesi mümkündür.

$\mathrm{Bu}$ bağlamda, hayvan barınaklarının çevresinde belli bir alanda yerleştirilecek koku algılayıcıların kullanılmasıyla anlık hava kalitesi gözlemlerinin yapılması mümkün olabilecektir. Günümüz teknolojisiyle söz konusu sistemlerden mobil cihazlara ve masaüstü bilgisayarlara anlık olarak işlenmiş veri aktarımı mümkündür. Dolayısıyla, hayvancılık işletmelerinin sebep olduğu koku problemlerinin gözlemlenip çözümler üretilebilmesi, komşular arasındaki ihtilafların giderilmesi ve diğer yasal ve teknik konularda çözümler geliştirilebilmesi için bu konuda daha ileri düzeyde çalışmaların yapılması önerilmektedir.

\section{Teșekkür}

$\mathrm{Bu}$ tez çalışması Çanakkale Onsekiz Mart Üniversitesi Bilimsel Araştırma Projeleri Koordinasyon Birimince desteklenmiştir. Proje numarası: 703

\section{Kaynakça}

Barisci J., Andrew M., Harris P., Patridge A., Wallace, G., 1997. Development of an Electronic Nose. Proc. of Smart Electric Nose, Spie, 3242: 164-171.

Bras R. L., Rodriguez-Iturbe I., 1985. Random Functions and Hydrology. Reading Mass. Addison Wesley. 359-425.

Brattoli M., de Gennaro G., de Pinto V., Loiotile A. D., Lovascio S., Penza M., 2011. Odour Detection Methods: Olfactometry and Chemical Sensors, Sensors, 11: 5290-5322.

Davis M. W., Culhane P.G., 1984. Contouring Very Large Data Sets Using Kriging; Geostatistics for Natural Resources Characterization, Part 2. Dordrecht. The Netherlands. Reidel. 599-619.

GD 780, 2006. Government Decision Regarding the Establish $\neg$ ment of Emissions Trading in Greenhouse Gas Emissions, As Amended by GD 133. Issue: 554

Görgülü M., Darcan N., Göncü S., 2009. Hayvancılık ve Küresel Isınma. V. Ulusal Hayvan Besleme Kongresi (Uluslararası Katılımlı). Çorlu, 30 Eylül-3 Ekim 2009.

Hosseini E., Gallichand J., Caron J., 1993. Comparison of Several Interpolators for Smoothing Hydraulic Conductivity Data in South West Iran. American Society of Agricultural Engineers. 36(6): 1687-1693.

Panigrahi S., Kizil U., Balasubramanian S., Doetkott C., Logue C., Marchello M., Gu H., Kubiak A., Nolan L., Schneider J., Wiens R., 2002. Electronic Nose System For Meat Quality Evaluation. 2002 ASAE/CIGR Annual International Meeting, Makale No., 026094, Chicago, Illinois, USA. 
Vac S.C., Popita G.E., Frunzeti N., Popovici A., 2013. Evaluation of Greenhouse Gas

Emission from Animal Manure Using the Closed Chamber Method for Gas Fluxes. Not Bot Horti Agrobo, 41(2):576-581.

Wathes C. M., Holden M. R., Sneath R. W., White R.P., and Phillips V. R., 1997.

Concentrations and Emission Rates of Aerial Ammonia, Nitrous Oxide, Methane, Carbon Dioxide, Dust and Eendotoxin in UK Broiler and Layer Houses. British Poultry Science, 38: $14-28$. 